\section{Standardisation of Scientific Glassware.}

THE Joint Committee for the Standardisation of Scientific Glassware, which was promoted by the Institute of Chemistry (30 Russell Square, W.C.I), and includes thirty-seven members representing mainly users and manufacturers, has published its first report, entitled "Units of Volume," in which is recorded the unanimous recommendation to discard the cubic centimetre as the standard unit for scientific glassware and to institute therefor the litre and the millilitre. Since, however, some chemists still prefer to use the Mohr unit, the Committee has added two further recommendations to obviate confusion between the two systems, although it hopes that in time the litre and the millilitre will be adopted exclusively. Vessels graduated on the Mohr system, it is recommended, should be marked "G.W.A." (grammes of water in air), and the numerical relation between the units shall be 1000 G.W.A. $=1002 \mathrm{ml}$. The National Physical Laboratory will test vessels of both kinds, but those graduated on the Mohr system will be marked differently from the others.

Whereas the volume of a body of simple geometrical form is readily calculated from its linear dimensions, the volume of a hollow vessel designed to hold a fluid is determined more easily and more accurately by finding the weight of water required to fill it. But the use of two distinct types of units has many disadvantages, especially if there is no simple numerical relation between them. To establish such a relation, the originators of the metric system defined the kilogram as the mass of water which occupies one cubic decimetre at its temperature of maximum density; so that the unit of volume, the litre, could be defined either as a cubic decimetre or as the space occupied by a kilogram of water at the specified temperature. A cubic decimetre of water was, however, not a practical standard weight, and the kilogram was therefore re-defined as the mass of a particular standard weight (kilogramme des Archives). In accordance with this change, the litre was re-defined as the volume occupied by one kilogram of pure water at its temperature of maximum density and under normal atmospheric pressure. Thus the litre became independent of the metric unit of length, and the cubic centimetre lost its relation to the volume of a mass of water. The precise relation between the litre and the cubic centimetre was found experimentally to be I litre $=1000.027$ c.c. $( \pm 0.001)$, a difference so small as to be negligible for ordinary volumetric glassware.

The introduction of the Mohr system caused confusion, inasmuch as by it the unit volume was defined in terms of the apparent weight in air of a mass of water at room temperature. By this system a "litre" flask contains Iooo gm. of water (weighed in air against brass weights) at $17.5^{\circ} \mathrm{C}$., which is the equivalent of 1002 c.c. as defined above; but the followers of Mohr designated the volume occupied by the Iooo $\mathrm{gm}$. of water one litre, and the thousandth part of it one cubic centimetre. The exact relation between the Mohr unit and the millilitre is given by the fact that the amount of water which weighs Iooo $\mathrm{gm}$. in air of density $0.0012 \mathrm{gm} . / \mathrm{ml}$., when weighed against brass weights of density $8.4 \mathrm{gm} . / \mathrm{ml}$, occupies a volume of $1002.02 \mathrm{I} \mathrm{ml}$. at $60^{\circ} \mathrm{F}$. The difference between this figure and I002, namely, 2 parts in 100,000 , is negligible in practice, and hence the Committee recommends the adoption of the round number, thus facilitating inter-conversion of "G.W.A." and millilitres.

The Committee has also considered the accuracy of volumetric glassware, and recommends the adoption of only two grades, namely, Class A, or Standard Apparatus, which must pass the N.P.L. or other approved test, and the Class B, or Commercial Grade Apparatus, of cheaper quality and for general use, which must, however, be guaranteed by the manufacturer to comply with certain minimum requirements. The Class A Tests and the Class B Tests of the National Physical Laboratory (as revised in a recent pamphlet to be obtained from The Director, N.P.L., Teddington, Middlesex) are approved, and confidence is expressed that manufacturers will be able to supply guaranteed Class B apparatus at reasonable prices. Finally, the Committee urges strongly that volumetric glassware should never be ordered without specifying the limits of accuracy required.

\section{Cod and Cod Fishery.}

THE three papers included in No. 7, vol. vi., series ii., Fishery Investigations, Ministry of Agriculture and Fisheries (H.M.S.O., price $3 s$.), record an investigation undertaken as part of the general programme of research on the cod which was initiated by the International Council for the Exploration of the Sea in I92I.

The first, under the initials of Mr. W. C. Smith, deals with the Irish Sea cod fishery. This fishery is of importance only during the winter months, and it is carried on chiefly by Manx longline fishermen and a few Fleetwood steam-liners. With the approach of winter and the decreasing temperature of the water, large mature cod move into the Irish Sea from the north to spawn. The return movement begins in April and is usually completed by the end of that month. Spawning takes place during February, March, and April in the waters around the Isle of Man and off the Cumberland coast. The young immature fish remain in these waters throughout the year.

The second paper, by Prof. Jas. Johnstone, gives an account of the cod as a food fish. It contains a summary of most of the results of analvses of cod and cod products, which may be found in König's big volume and in the work by Atwater. The results obtained from Irish Sea cod are also included. The results show that the cod is a "fatpoor. "fish. Less than about half of the total weight of the entire fish is edible. In the edible substance, about $8 \mathrm{I}$ per cent. to 84 per cent. is water, and there is práctically no fat; about I per cent. is ash, and the rest (about $\mathrm{I}_{4}$ to $\mathrm{I} 7$ per cent.) is protein.

The third paper, by Prof. Johnstone and Mr. A. Scott, summarises information on the parasites and diseases of the cod. Ectoparasites and endoparasites are set out under orders and families, and a note on the occurrence of each is given. Both are less numerous in the cod than in many other species of fishes. The whiting and haddock, for example are much more affected than is the cod. Cases of sarcomatous and other tumours, lupus and ulceration of the body, "columnar disease" in the muscle, diseased liver, stone in the urinary bladder, and ovarian degeneration are on record. Humpbacked cod in which the head is fairly normal in shape, while the trunk and tail regions are shortened and the backbone is thrown into a gently spiral form, are occasionally seen. One-eyed cod suggestive of irregular development rather than of injury are also recorded. References to literature on hermaphroditism are given in the concluding section of this instructive paper.

No. 2865 , VOL. I 14$]$ 